\title{
Design and Performance of Archimedes Single Screw Turbine as Micro Hydro Power Plant with Flow Rate Debit Variations (Case Study in Air Dingin, Samadua - South Aceh)
}

\author{
Irwansyah $^{\mathrm{a}, 1,{ }^{*}}$, Muhammad Ilham Maulana ${ }^{\mathrm{b}, \mathrm{c}, 2}$, Ahmad Syuhada ${ }^{\mathrm{b}, 3}$ \\ ${ }^{a}$ South Aceh Polytecnic, Jl. Reklamasi Pantai Tapaktuan and 23711, Indonesia \\ ${ }^{b}$ Faculty of Mechanical Engineering Unsyiah, Kopelma Darussalam Syiah Kuala Banda Aceh and 23111, Indonesia \\ ${ }^{c}$ Faculty of Mechanical Engineering Unsyiah, Kopelma Darussalam Syiah Kuala Banda Aceh and 23111, Indonesia \\ ${ }^{1}$ irwansyah2182@poltas.ac.id*; ${ }^{2}$ ilhammaulana@unsyiah.ac.id; ${ }^{3}$ Ahmadsyuhada@unsyiah.ac.id \\ *irwansyah2182@poltas.ac.id
}

Renewable energy is energy derived from nature and can be produced continuously such as water energy as a micro hydropower plant. The development of a micro hydropower plant is to utilize the potential energy of water flow that has a certain head and discharge to be converted by turbines and generators into energy electricity that

Keywords: can be used in the development of Archimedes Single Screw Turbines. Archimedes Single Screw Turbine is a type of turbine that Renewable Energy

Micro Hydro is capable of operating with low head 1-15 meter in river flow and irrigation. Aceh is one of the regions that have a large amount of water energy potential to be used as energy driving water turbines.

Blade The purpose of this study is to design, make Turbine Archimedes

Head Single Screw construction and conduct turbine testing and determine

Torque the performance of Archimedes Single Screw Turbine based on the Effeciency effect of water flow discharge on rotation, torque, power, and optimum efficiency so that it can determine the right turbine design and performance well. Archimedes Single Screw turbine is made with 201 stainless steel which has dimensions of $\mathrm{N}=1$ blade $(\mathrm{Ro}=$ $130 \mathrm{~mm}, \mathrm{Ri}=70 \mathrm{~mm})$ with pitch $2 \mathrm{Ro}$, Turbine length $(\mathrm{L}=2 \mathrm{~m})$, head $=1 \mathrm{~m}$, Angle $\theta=30^{\circ}$. The variables measured and observed are the rotation of the turbine, torque, and flow rate. Tests were carried out on 3 variations of flow rate, namely $0.02 \mathrm{~m}^{3} / \mathrm{s}, 0.009 \mathrm{~m}^{3} / \mathrm{s}$, and $0.003 \mathrm{~m}^{3} / \mathrm{s}$. The test results, the highest rotation, and turbine power occur at flowrate $0.02 \mathrm{~m}^{3} / \mathrm{s}$ at $236.40 \mathrm{rpm}$ with a power of 116.10 watts and maximum turbine efficiency is $57 \%$. Thus, the turbine with maximum power and efficiency is obtained when the flow rate is $0.02 \mathrm{~m}^{3} / \mathrm{s}$.

\section{Introduction}

Renewable energy is energy that comes from nature and can be produced continuously without the need to wait in millions of years such as fossil-based energy (non-renewable). Renewable energy can be produced from sunlight, geothermal energy, wind, water (hydropower) and various forms of biomass [1]. This Archimedes Screw has several advantages among other types of low head turbines and does not require a special control system because of the use of standard equipment and generator units, easy in construction, easy in installation and maintenance, environmentally friendly and fish-friendly, high turbine efficiency for low head and high discharge operating conditions [2]. Screw turbine optimization (Archimedes Screw) was examined by Chris Rorres in his research entitled The Turn of the Screw: Optimal Design of An Archimedes Screw. The results showed that the geometry of an Archimedes Screw was determined by external parameters, namely the outer radius, screw length, and slope. These external parameters are usually determined by the location of the Archimedes Screw and how much water is lifted. Other parameters that affect are internal parameters such as inner radius, number of blades, and blade pitch [3]. Muhammad Ilham Maulana, 
et al. "Assessed the Initial Archimedes Screw Turbine as a Low-Head Power Plant on a laboratory scale", and obtained the maximum rotation of small Archimedes screw turbine prototypes at a flow rate of $0.09 \mathrm{~m}^{3} / \mathrm{s}$ with a laying angle of $30^{\circ}$. Increasing the flow rate further results in a lower rotation speed [4]. The performance of an Archimedes Screw is influenced by the related parameters in the design of the screw turbine itself. One important parameter in screw turbine design is the dimensions of the thread and pitch. Based on the research conducted by previous researchers, it was found that Archimedes Single Screw Turbine has a very good flow rate. So in this study some studies will be conducted on the performance of Turbine Archimedes Single Screw experimentally in the location of Samadua South Aceh cold water river flow with variations in water flow rate (Q) and $30^{\circ}$ turbine angle slope in Archimedes Single Screw Turbine with 1 meter head.

\section{Literature Review}

\section{A. Turbine Archimedes Screw}

Archimedes Screw is a turbine that is very special because it can operate in areas that have very low heads. In its use, this screw turbine depends on the head condition in the field. The screw turbine works at a low head with the water level falling between 1-15 $\mathrm{m}$. The slope angle for determining the turbine head is between $30^{\circ}-60^{\circ}$ [4].

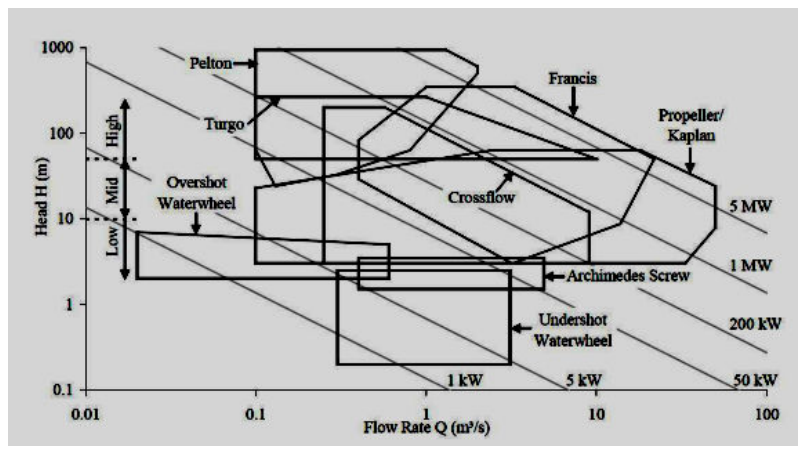

Figure 1. Classification of Thread Turbine with Head and Output Power

The working principle of this screw turbine where the pressure from the water through the turbine screw blades experiences a pressure drop in line with the decrease in water velocity due to the resistance of the turbine threads, this pressure will rotate the turbine and drive the electric generator after the power of the shaft is transmitted through the gearbox [4].

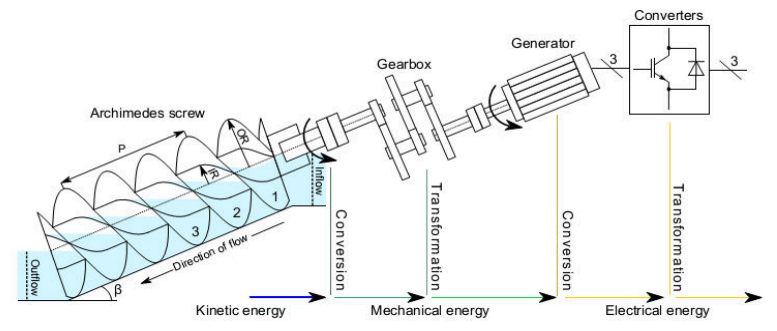

Figure 2. Turbine Schematic of Archimedes Screw

Some of the advantages of screw turbines compared to other types of water turbines are [5]:

a. It is well developed in areas that have a water source with a fairly large discharge (river) but only has a low head up to 1 (one) meter.

b. Does not require a very complicated control system like other turbines.

c. Can be operated without filters and does not disturb the river ecosystem.

d. Has high efficiency and reliability, with a large variation of discharge and is very good for small water discharge.

e. The age of the turbine is more durable especially if it is operated at low speed and is cheap in its maintenance. 
f. It does not require fine nets to prevent the entry of debris into the turbine, which can reduce maintenance costs.

\section{B. Design of Screw Turbine Demensions}

The geometry of a turbine or Archimedes screw pump is determined by the external dimensions and dimensions in the turbine [5].

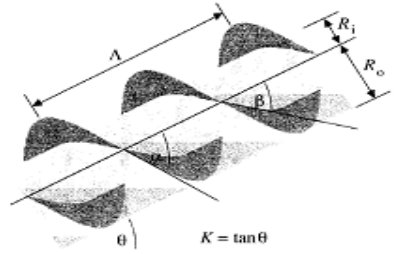

Figure 3. Profile of Archimedes Screw Turbine

Where :

$\boldsymbol{R}_{\boldsymbol{i}}=$ Radius in screw blade $\left(0<\boldsymbol{R}_{i}<\boldsymbol{R}_{o}\right)$.

$R_{o}=$ Outer radius of turbine blade.

$\Lambda=$ Turbine blade thread range $\left(0 \leq \Lambda \leq 2 \pi R_{0} / \mathrm{K}\right)$.

$\mathrm{K}=\tan \theta$.

$\theta \quad=$ The tilt angle of the turbine shaft.

$\alpha \quad=$ Screw angle (at Ro position).

$\mathrm{N}$ = Number of threads $(1,2, \ldots)$.

The outer dimensions of the turbine consist of the outer radius of the $R_{0}$ screw, the screw range $\Lambda$, and the axle slope angle $\theta$. The outer dimensions are determined by the location of the screw placement, the screw material to be used and the water discharge. The tilt angle $\theta$ turbine is generally between $30^{\circ}$ to $60^{\circ}$. While the inner dimensions of the turbine include the radius in $R_{i}$, the number of $\mathrm{N}$ blades, and the distance between the threads if $\mathrm{N}>1$. The dimensions in the free turbine are chosen, so that optimization of the screw turbine can be done by changing and varying it. The length of the screw shaft $\mathrm{L}$ can be calculated by equation (1) :

$$
\mathrm{L}=\frac{H}{K}
$$

Rorres offers a formulation for determining Archimedes thread dimensions based on calculating the maximization of water volume between threaded ranges, the maximum volume of which is expressed in equation (2).

$$
v_{T}^{*}=\pi R_{\sigma}^{2} \Lambda^{*} v^{*}
$$

At the maximum volume, the inner diameter can be obtained from equation (3).

$$
\boldsymbol{R}_{i}=\rho \cdot \boldsymbol{R}_{i}
$$

Threaded range at maximum volume is expressed by equation (4).

$$
\Lambda=\frac{2 \pi R_{0} \lambda}{K}
$$

The relationship between the ratio of optimum volume $\mathrm{v}$, optimum radius and optimum range $\mathrm{N}$ is shown in Table 1. Then for the volume, radius and thread range equations are defined in equations (5), (6), and (7) below :

$$
\begin{aligned}
& V=\frac{V_{T}}{\pi R^{2}} \\
& \rho=\frac{R i}{R o} \\
& \lambda=\frac{K \Omega}{2 \pi R_{0}}
\end{aligned}
$$

The amount of $m$ range required at the screw turbine shaft length $L$ for optimum range length $\Lambda^{*}$ can be calculated by equation (8) :

$$
\mathrm{m}=\frac{\boldsymbol{L}}{\boldsymbol{A}}
$$

Equation (1) d.d (8) together with Table 1 are used to determine Archimedes threaded turbine design dimensions in this research activity. The maximum screw turbine rotation is n_maks (rpm) and the relationship between dimensions ranges $\Lambda$ and the outer radius of $R_{\theta}$ blade for various turbine slope angles can be expressed in equations (9) and (10) [5]. 


$$
\begin{aligned}
& \boldsymbol{n}_{\text {maks }}=\frac{50}{2 \cdot R_{\theta}^{n / s}} \\
& \Lambda=2,4 \text { Ro untuk } \theta<30^{\circ} \\
& \Lambda=2,0 \text { Ro untuk } \theta=30^{\circ} \\
& \Lambda=1,6 \text { Ro untuk } \theta>30^{\circ}
\end{aligned}
$$

Table 1. Screw Turbine Parameters

\begin{tabular}{c|c|c|c|c}
\hline $\begin{array}{c}\text { Number Of } \\
\text { Blades } \\
\mathrm{N}\end{array}$ & $\begin{array}{c}\text { Optimal } \\
\text { Radius Ratio } \\
\rho^{*} \\
(2)\end{array}$ & $\begin{array}{c}\text { Optimal } \\
\text { Pitch Ratio } \\
\lambda^{*} \\
(3)\end{array}$ & $\begin{array}{c}\text { Optimal } \\
\text { Volume } \\
\text { Pertum Ratio } \\
\lambda^{*} \mathrm{v}\left(\mathrm{N}, \rho^{*}, \lambda^{*}\right) \\
(4)\end{array}$ & $\begin{array}{c}\text { Optimal } \\
\text { Volume } \\
\text { Ratio } \\
\mathrm{v}\left(\mathrm{N}, \rho^{*}, \lambda^{*}\right) \\
(5)\end{array}$ \\
\hline $\mathbf{1}$ & $\mathbf{0 . 5 3 5 8}$ & $\mathbf{0 . 1 2 8 5}$ & $\mathbf{0 . 0 3 6 1}$ & $\mathbf{0 . 2 8 1 1}$ \\
$\mathbf{2}$ & $\mathbf{0 . 5 3 6 9}$ & $\mathbf{0 . 1 8 6 3}$ & $\mathbf{0 . 0 5 1 2}$ & $\mathbf{0 . 2 7 4 7}$ \\
3 & 0.5357 & 0.2217 & 0.0598 & 0.2697 \\
4 & 0.5353 & 0.2456 & 0.0655 & 0.2667 \\
5 & 0.5352 & 0.2630 & 0.0696 & 0.2647 \\
6 & 0.5353 & 0.2763 & 0.0727 & 0.2631 \\
7 & 0.5354 & 0.2869 & 0.0752 & 0.2619 \\
9 & 0.5356 & 0.3029 & 0.0788 & 0.2601 \\
10 & 0.5356 & 0.3092 & 0.0802 & 0.2592 \\
11 & 0.5358 & 0.3145 & 0.0813 & 0.2586 \\
12 & 0.5360 & 0.3193 & 0.0824 & 0.2580 \\
13 & 0.5360 & 0.3234 & 0.0833 & 0.2574 \\
14 & 0.5360 & 0.3270 & 0.0841 & 0.2571 \\
15 & 0.5364 & 0.3303 & 0.0848 & 0.2567 \\
16 & 0.5362 & 0.3333 & 0.0854 & 0.2562 \\
17 & 0.5362 & 0.3364 & 0.0860 & 0.2556 \\
18 & 0.5368 & 0.3380 & 0.0865 & 0.2559 \\
19 & 0.5364 & 0.3404 & 0.0870 & 0.2555 \\
- & - & - & - & - \\
- & - & - & - & - \\
- & - & - & - & - \\
$\infty$ & 0.5394 & 0.3953 & 0.0977 & 0.2471 \\
\hline
\end{tabular}

The power produced by a turbine with certain efficiency can be determined by equation (11) :

$P_{t h}=p . \mathrm{g} \cdot \mathrm{Q} \cdot \mathrm{H} . \eta$

Where :

$P_{t h}=$ Turbine Power (Watts)

$\rho \quad=$ Mass type of water $(\mathrm{kg} / \mathrm{m} 3)$

$\mathrm{Q}=$ Debit $(\mathrm{m} 3 / \mathrm{s})$

$\mathrm{g}=$ Gravity acceleration $(\mathrm{m} / \mathrm{s} 2)$

$\mathrm{H}=$ "net head" / effective height.

$\eta \quad=$ Turbine efficiency.

So to get turbine discharge can be searched using equation (12).

$$
\begin{aligned}
& P_{t h}=\rho \mathrm{g} \mathrm{QH} \eta \\
& Q=\frac{p}{\rho \eta \mathrm{H} g}
\end{aligned}
$$

The efficiency of a turbine is affected by power. Archimedes screw turbine efficiency is a comparison between turbine power and fluid power. The efficiency of can be determined by equation (13) as follows :

$$
\eta=\frac{\text { POutput }}{\text { PInput }} \times 100 \%
$$

Determination of turbine efficiency depends on the type of turbine used, where in the design the load is taken at maximum conditions, namely full load or $100 \%$ as in Figure 4.

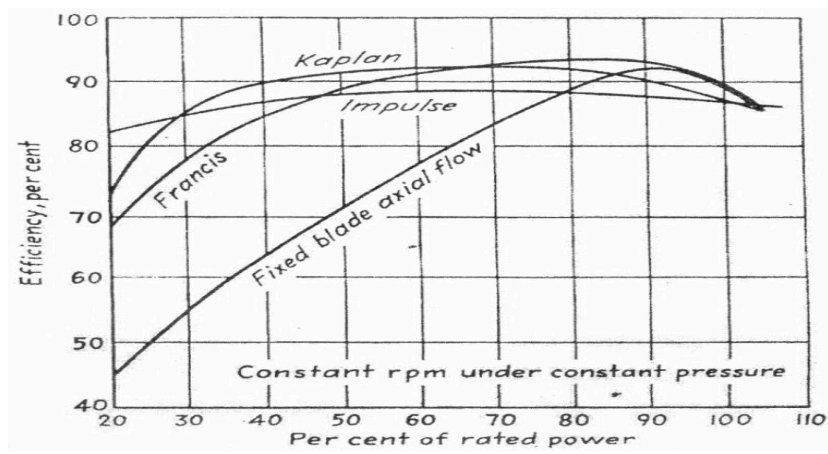

Figure 4. Profile of Archimedes Screw Turbine 
At certain power, channel efficiency can be increased by increasing the size of the pipe, but this means an increase in costs. For certain channels, efficiency will increase when the power is reduced. Therefore, for certain channels can be determined the maximum power that can be produced, and for certain power the best diameter can be determined.

\section{Debit Calculation}

In determining the shape of the discharge turbine it is very necessary to know the crosssectional area of the water channel that enters the turbine, where the cross-sectional area of the water channel that enters the turbine depends on the flow of water. This is in accordance with the continuity equation $\mathrm{Q}=\mathrm{A}$. V The flow of fluid flowing will definitely have a certain flow velocity, the relationship of flow velocity with discharge and cross-sectional area can be written in equation 14 below.

$$
Q=A x V
$$

Where :

$$
\begin{aligned}
Q & =\text { Water discharge }\left(\mathrm{m}^{3} / \mathrm{s}\right) \\
V & =\text { Water speed }(\mathrm{m} / \mathrm{s}) \\
A & =\text { Cross-sectional area }\left(\mathrm{m}^{2}\right)
\end{aligned}
$$

\section{Method}

In analyzing the performance of Turbine Archimedes Single Screw, there are several methods that are carried out including the following :

1. Conduct a survey of potential water energy sources in the location of Samadua South Aceh cold water to be used using screw turbines.

2. Performing the dimensions of Turbine Archimedes Single Screw dimensions.

3. Fabricating Archimedes Single Screw Turbines according to the design drawings.

4. Conducting experiments on the performance of Turbine Archimedes Single Screw to determine the results of rotation $(\mathrm{n})$, torque $(\mathrm{T})$, power $(\mathrm{P})$ and optimum efficiency.

\section{Results and Discussion}

\section{A. Specification of Archimedes Single Screw Turbine}

Table 2. Screw Turbine Design Data Parameters ( $\mathrm{N}=1$ Blade, Head $=1 \mathrm{~m}$, Angle $(\theta): 30^{\circ}$, Flowrate $\left(Q_{1}\right)=0,02 \mathrm{~m}^{3} / \mathrm{s}$, Flowrate $\left(Q_{2}\right)=0,009 \mathrm{~m}^{3} / \mathrm{s}$, Flowrate $\left(Q_{\mathfrak{a}}\right)=0,003 \mathrm{~m}^{3} / \mathrm{s}$

\begin{tabular}{lcc}
\hline \multicolumn{1}{c}{ Parameters } & Value & Unit \\
\hline Turbine length $(\mathrm{L})$ & 2 & $\mathrm{~m}$ \\
Outer shaft diameter & 110 & $\mathrm{~mm}$ \\
Inner shaft diameter & 25,4 & $\mathrm{~mm}$ \\
Outer radius 1 blade $\left(\boldsymbol{R}_{\boldsymbol{o}}\right)$ & 130 & $\mathrm{~mm}$ \\
Inner radius 1 blade $\left(\boldsymbol{R}_{i}\right)$ & 70 & $\mathrm{~mm}$ \\
Pitch 1 blade $(\boldsymbol{A})$ & 130 & $\mathrm{~mm}$ \\
Blade Thikcness & 2 & $\mathrm{~mm}$ \\
Jumlah Ulir 1 blade $(\mathrm{N})$ & 14 & $\mathrm{Unit}$ \\
Casing length & 2250 & $\mathrm{~mm}$ \\
The width of the turbine case & 240 & $\mathrm{~mm}$ \\
Stand Length & 1900 & $\mathrm{~mm}$ \\
\hline
\end{tabular}

Based on the data parameters from the calculation of the dimensions of Turbine Archimedes Single Screw), the results of the design of the engineering drawings that are designed have a slope of $30^{\circ}$ angles and can be seen in Figure 5 . 


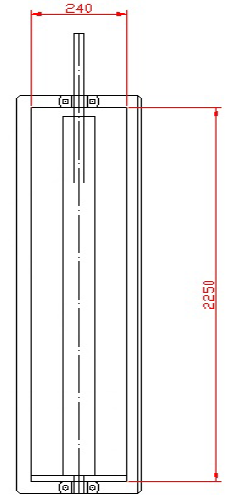

Top View

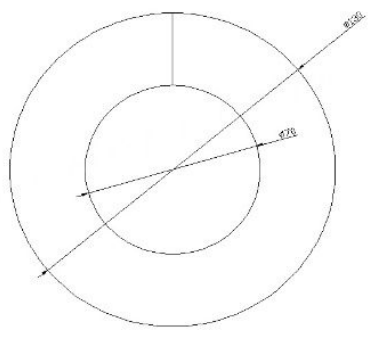

$\mathrm{N}=$ Single Blade

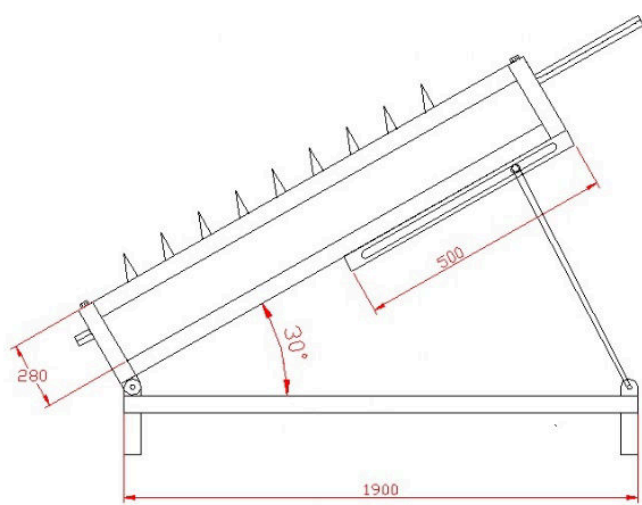

Slide View

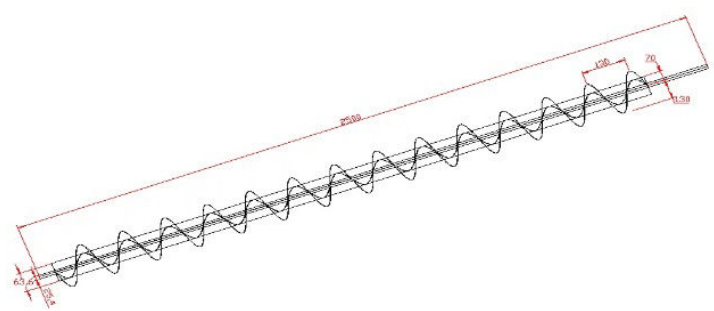

Design of Single Blade

Figure 5. Design Archimedes Single Screw Turbine

\section{B. Fabrication Archimedes Single Screw Turbine}

For the stage of fabrication Archimedes Screw, this is based on the design of Single Archimedes Screw Turbine designs that have been designed according to the size of the main dimensions. Turbine Single Archimedes Screw mechanical components consist of screw turbine, turbine shaft and bearing, turbine screw house (U-shaped screw casing), screw turbine seat frame.
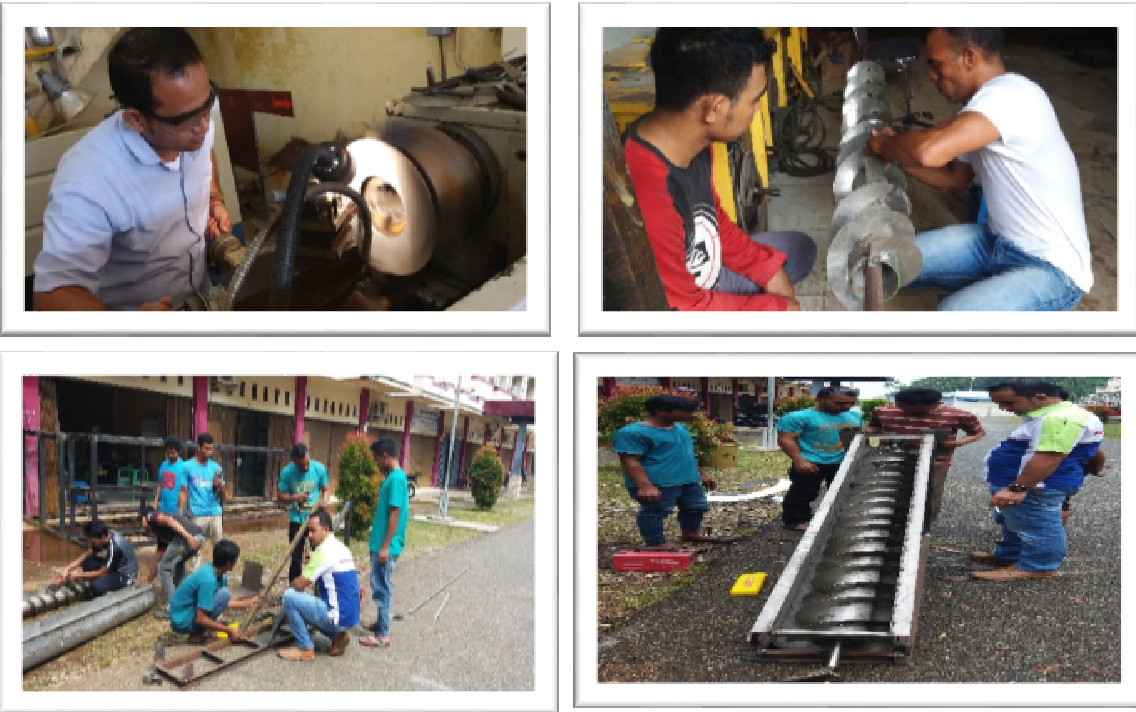

Figure 6. Fabrication Archimedes Single Screw Turbine

\section{Experiments and Measurements}

The testing phase and measurement of Turbine Archimedes Single Screw to be carried out in this study is to pay attention to several parameters such as the slope of the laying angle of the turbine which is equal to $30^{\circ}$, variations in flowrate $(\mathrm{Q})$, rotation speed (n) and torque (T) on the threaded 
turbine shaft optimum power (P) and optimum efficiency $(\eta)$ produced by Turbine Archimedes Single Screw.
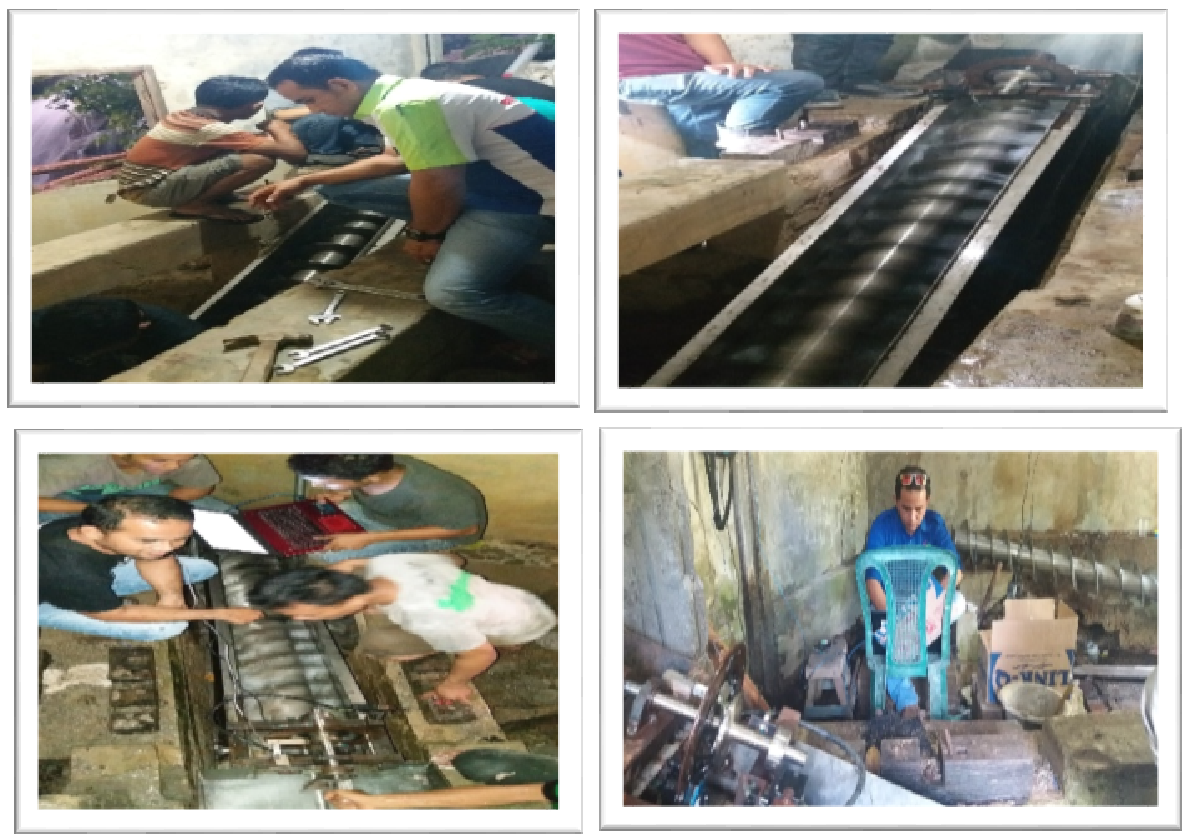

Figure 7. Activities for Testing and Collecting Performance Data Archimedes Single Screw

\section{Effect of Flow Discharge Variations (Q) on the Slope of the Turbine Angle in Archimedes}

Single Screw Turbine

V-Notch is used to measure the flow of water, the V-Notch specification in the research location has a length of $=2 \mathrm{~m}$, width of $0.5 \mathrm{~m}$ and height $=0.32 \mathrm{~m}$, from the measurement of water level to produce $\mathrm{H}=0.18 \mathrm{~m}$ used for measurement of water discharge in $\mathrm{Q} 1, \mathrm{H}=0.13 \mathrm{~m}$ is used to measure water discharge in Q2, and $\mathrm{H}=0.08 \mathrm{~m}$ is used for measuring water discharge in Q3. Determination of water flow discharge is measured actually by knowing the height of falling water from the VNotch tip. The results of measuring flowrate using Weir Discharge Table $90^{\circ}$ Degree V-Notch, the experimental results in measuring water flow discharge $(\mathrm{Q})$ can be seen in Table 3.

Table 3. Experimental Results of Water Flow Discharge

\begin{tabular}{ccc}
\hline $\boldsymbol{Q}_{1}\left(\mathbf{m}^{3} / \boldsymbol{s}\right)$ & $\boldsymbol{Q}_{2}\left(\mathrm{~m}^{3} / \mathbf{s}\right)$ & $\boldsymbol{Q}_{3}\left(\mathrm{~m}^{3} / \mathbf{s}\right)$ \\
\hline 0,02 & 0,009 & 0,003 \\
\hline
\end{tabular}

In Table 3. shows the results of measurements of water discharge obtained including the highest water discharge is $0.02 \mathrm{~m}^{3} / \mathrm{s}$ and the lowest water discharge is $0.003 \mathrm{~m}^{3} / \mathrm{s}$.

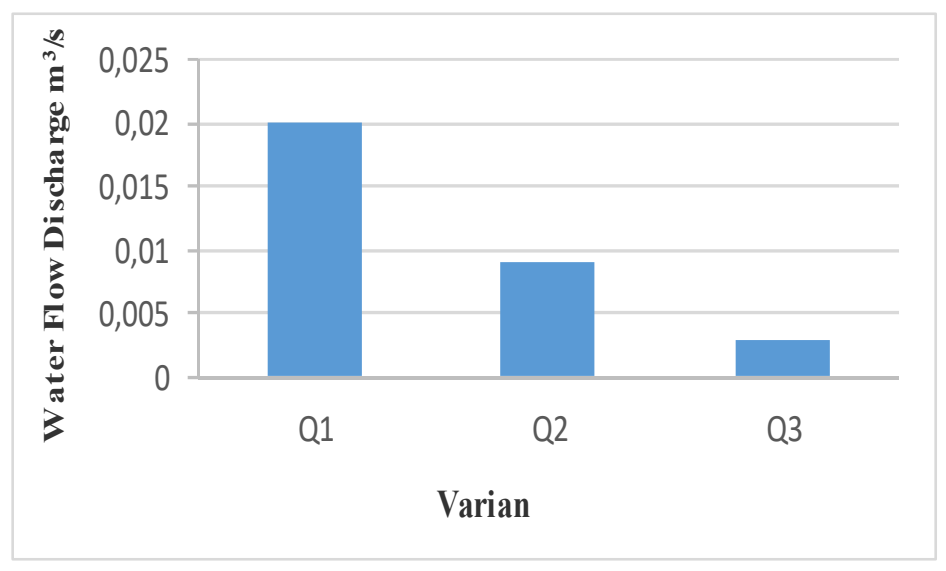

Figure 8. Experimental Results of Water Flow Discharge 


\section{E. Result of Experiments on Archimedes Single Screw Turbine}

Turbine Arcimedes Single Screw experiments were carried out to determine the performance of the screw turbine during the loading process. The experimental results were obtained from measurements of rotation (n), torque (T), power (P) and efficiency $(\eta)$ based on variations in flowrate (Q) on Single Archimedes Screw Turbines with slope of turbine angle $\theta=30^{\circ}$.

Table 4. Experimental Data From Measurement of Turn (n), Torque (T), Power $(P)$ and Efficiency $(\eta)$ in Single Screw Turbine

\begin{tabular}{ccccc}
\hline Debit Variation (Q) & Rotation (rpm) & Torque (Nm) & Power (Watt) & Efficiency (\%) \\
\hline $\boldsymbol{Q}_{\mathbf{1}}$ & 236,40 & 0,50 & 12,37 & 6 \\
$\mathbf{0 , 0 2} \boldsymbol{m}^{\mathbf{3} / s}$ & 218,30 & 1,00 & 22,85 & 12 \\
& 206,90 & 2,50 & 54,14 & 28 \\
$\boldsymbol{Q}_{\mathbf{2}}$ & 201,40 & 4,00 & 84,32 & 43 \\
\hline $\mathbf{0 , 0 0 9} \mathbf{m}^{\mathbf{3}} / \mathbf{s}$ & 180,30 & 0,20 & 3,77 & 4 \\
& 168,40 & 1,00 & 17,63 & 20 \\
$\boldsymbol{Q}_{\mathbf{3}}$ & 142,10 & 2,00 & 29,75 & 34 \\
$\mathbf{0 , 0 0 3} \mathbf{m}^{\mathbf{3}} / \mathbf{s}$ & 135,90 & 2,50 & 35,56 & 40 \\
\hline & 123,60 & 0,10 & 1,29 & 4 \\
& 110,40 & 1,00 & 11,56 & 39 \\
& 86,20 & 1,50 & 13,53 & 37 \\
\hline
\end{tabular}

In Table 4. above shows the experimental results data from measurements of rotation (n), torque $(\mathrm{T})$, power $(\mathrm{P})$, and efficiency $(\eta)$. From the table it can be explained that when the optimum water flow flow Q1 $0.02 \mathrm{~m}^{3} / \mathrm{s}$ with the slope of the turbine angle $30^{\circ}$ produces an optimum (n) rotation of $236.40 \mathrm{rpm}$, optimum torque (T) of $4.00 \mathrm{Nm}$, Power (P) The optimum is $84.32 \mathrm{Watts}$ and optimum Efficiency $(\eta)$ of $43 \%$. While the minimum water flow rate of Q3 $0.003 \mathrm{~m} 3 / \mathrm{s}$ produces a minimum (n) rotation of $52.60 \mathrm{rpm}$, minimum torque (T) of $2.00 \mathrm{Nm}$, minimum Power $(\mathrm{P})$ of 11.01 Watt and Efficiency $(\eta)$ minimum 37\%.

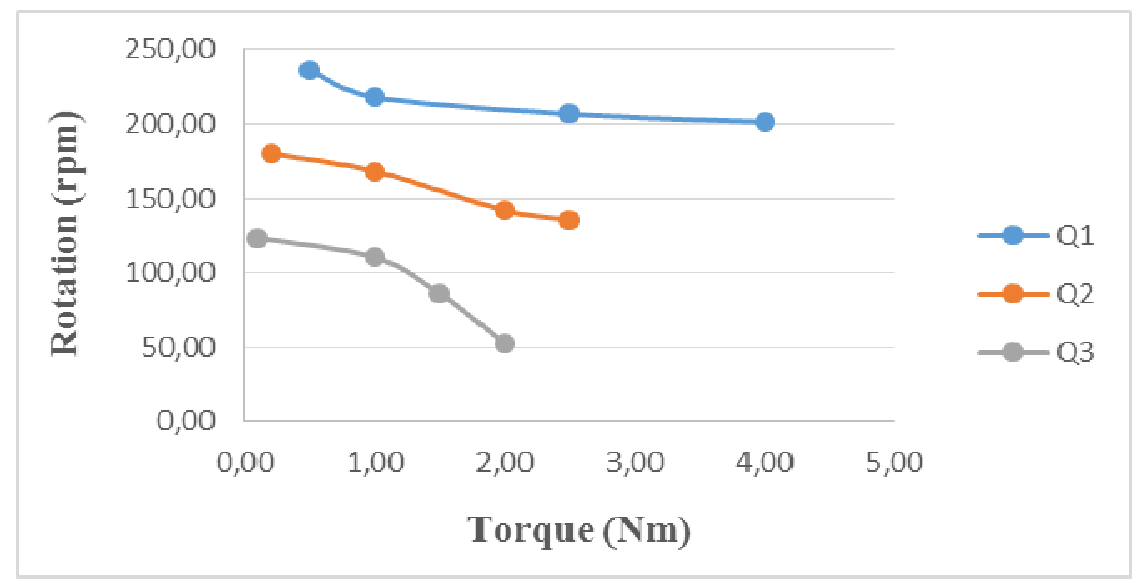

Figure 9. Relationship Chart of Torque Measurement Results (T) with Rounds (n) Based on Flow Debit Variations (Q)

The graph in Figure 9. explains the relationship between the measurement results between rotation $(\mathrm{n})$ and torque $(\mathrm{T})$ in all conditions of flow rate variation $(\mathrm{Q})$ with the slope of the turbine angle $30^{\circ}$. Then the graph shows that the highest rotation speed (n) occurs at the Q1 water discharge that is equal to $236.40 \mathrm{rpm}$, followed by rotation at Q2 water discharge of $135.90 \mathrm{rpm}$ and the lowest occurs at Q3 discharge which is equal to $52.60 \mathrm{rpm}$. 


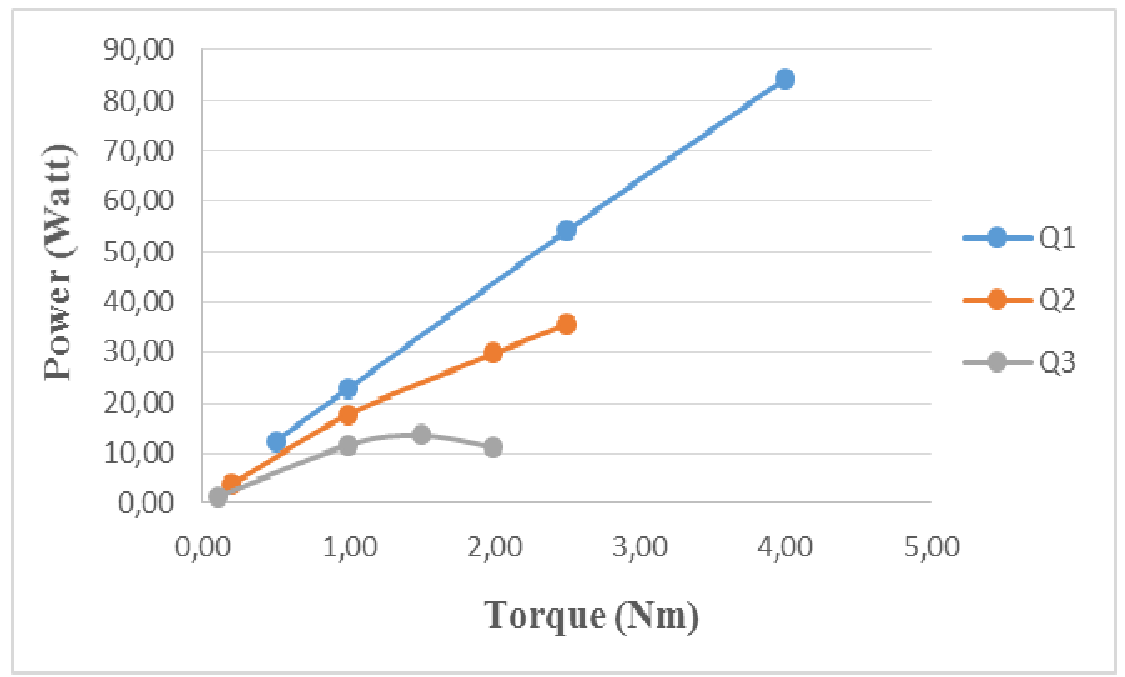

Figure 10. Graph Relationship of Torque Measurement Results (T) with Power (P) Based on Flow Discharge Variation (Q) Against the Turbine Angle

The graph in Figure 10. explains the relationship between the measurement results between torque $(\mathrm{T})$ and power $(\mathrm{P})$ in all conditions of variation in flowrate $(\mathrm{Q})$ with the slope of the turbine angle $30^{\circ}$. then the graph shows that the highest power $(\mathrm{P})$ occurs at the Q1 water discharge that is equal to 84.32 watts, followed by power $(\mathrm{P})$ at the $\mathrm{Q} 2$ water discharge of 35.56 watts and the lowest power $(\mathrm{P})$ occurs at the $\mathrm{Q} 3$ water discharge that is equal to 11.01 watts.

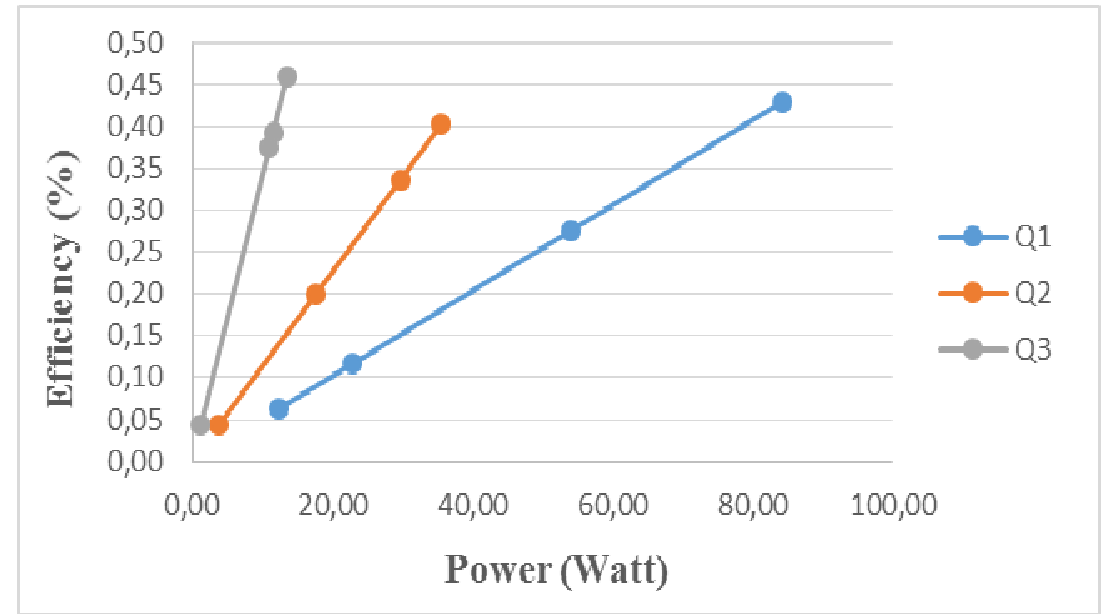

Figure 11. Graphs of Relationship between Results of Measurement of Power (P) with Efficiency ( $)$ Based on Flow Rate Variation (Q).

The graph in Figure 11. explains the relationship between the measurement results between power $(P)$ and efficiency $(\eta)$ in all conditions of variation in water discharge $(Q)$ with the slope of the turbine $30^{\circ}$. Then the graph shows that the highest efficiency $(\eta)$ occurs at the Q3 by $46 \%$, followed by efficiency at Q1 water discharge of 43\% and the lowest occurs in Q2 water discharge which is equal to $40 \%$.

\section{Conclusion}

From the results of designing, fabricating and testing the Archimedes Single Screw Turbine, some conclusions can be drawn as follows : 
1. The obtained Turbine Archimedes Single Screw turbine specifications are; single screw turbines that have dimensions $\left(\boldsymbol{R}_{0}\right)=130 \mathrm{~mm},\left(\boldsymbol{R}_{\boldsymbol{i}}\right)=70 \mathrm{~mm}$ and pitch $130 \mathrm{~mm}$, and have a turbine length of 2 meters.

2. the influence of variations in the flow rate of water $(\mathrm{Q})$ with the slope of the turbine angle $\theta$ $=30^{\circ}$ in the Archimedes Single Screw Turbine that is the higher the fall distance of water from the v-notch end, the greater the flow rate, the largest flowrate is $\mathrm{Q} 1=0.02 \mathrm{~m}^{3} / \mathrm{s}$ followed by $\mathrm{Q} 2=0.009 \mathrm{~m}^{3} / \mathrm{s}$ and the last is $\mathrm{Q} 3=0.003 \mathrm{~m}^{3} / \mathrm{s}$.

3. The test results, the highest rotation and turbine power occur at flowrate $0.02 \mathrm{~m} / \mathrm{s}$ at $236.40 \mathrm{rpm}$ with a power of 116.10 watts and maximum turbine efficiency is $57 \%$. Thus, the turbine with maximum power and efficiency is obtained when the flowrate is $0.02 \mathrm{~m}^{3} / \mathrm{s}$.

\section{Acknowledgment}

Thanks to the manager of the South Aceh Polytechnic Mechanical Engineering and CNC Mechanical Study Program, for the facilities provided and also to the supervisors from the Faculty of Engineering, Syiah Kuala University Dr. Muhammad Ilham Maulana, ST, .MT and Co. Advisor Prof. Dr. Ir. Ahmad Syuhada., M.Sc who has guided and motivated this single screw turbine archimedes research.

\section{References}

[1] Agency for the Assessment and Application of Technology, Indonesian Energy Outlook 2017. Jakarta: Center for Energy Resources and Chemical Industry (PTSEIK), 2017.

[2] A. Havendri and H. Lius, "Design and realization of a prototype model of water type screw (archimedean turbine) for microhydro power plants with low head in Indonesia," Technique A, vol. 31, no. 2, pp. 1-7, 2009.

[3] Chris Rorres. 2000. The Turn Of The Screw: Optimal Design Of An Archimedes Screw. Journal of Hydraulic Engineering, Vol. 126, No. 1, pp. 72-80. Philadelphia.

[4] Muhammad Ilham Maulana, et al. 2015. Preliminary Review of Archimedes Screw Turbines as LowHead Power Plants on the Laboratory Scale. Banda Aceh. Syiah Kuala University.

[5] Nagel, G. (1968). Archimedean screw pump handbook.Prepared for Ritz-Atro Pumpwerksbau GMBH Roding, $\mathrm{Nu}$ " rnberg, Germany.

[6] T. Beckwith, R. Marangoni, and J. Lienhard, "Mechanical Measurements," 2007.

[7] Computational Fluid Dynamics (CFD), https://fauzanahmad. wordpress.com/ (diakses 24 Mei 2018).

[8] Tuakia Firman, 2008, Fundamentals of CFD Using Fluent, Informatics, Bandung. 